\title{
Teaching Method Reform and Exploration of C Language Programming Training Course Based on Case
}

\author{
Xian Zhang ${ }^{1,2,3}$, Taiguo $\mathrm{Qu}^{1,3, *}$, Yinwen $\mathrm{Liu}^{1,2,3}$, Dong Yin ${ }^{1,2,3}$ \\ ${ }^{1}$ School of Computer Science and Engineering, Huaihua University, Huaihua 418000, Hunan, P. R. China \\ ${ }^{2}$ Key Laboratory of Intelligent Control Technology for Wuling-Mountain Ecological Agriculture in Hunan Province, \\ Huaihua 418000, Hunan, P. R. China \\ ${ }^{3}$ Key Laboratory of Wuling-Mountain Health Big Data Intelligent Processing and Application in Hunan Province \\ Universities, Huaihua 418000, Hunan, P. R. China \\ *Corresponding author
}

\begin{abstract}
In view of the weak foundation of computer major students in local Colleges, a case-based teaching method is used to stimulate students' learning motivation and interest. The case-based teaching method takes the case task as the carrier carefully designs the combination of case task and knowledge point, and integrates the case task into the real scene. At the same time, the case is divided into three levels: simple, general and slightly difficult to deal with students at different levels. All cases are arranged on the online automatic judge system. Through the online automatic judge system, students can complete the case work, which can make students better learn knowledge points and complete the case, and make students better experience the sense of challenge and joy after the success of the challenge. The case-based teaching method can achieve a good teaching effect through the completion of homework and final examination results.
\end{abstract}

Keywords: Local colleges, Case, Knowledge points, Online judge system, Teaching effectiveness

\section{INTRODUCTION}

C language programming course is the most basic and important programming course in computer major and related majors [1]. Most colleges and universities choose C language programming course as the first introductory course of programming language class, so the learning quality of $\mathrm{C}$ language programming course directly affects the learning of the following courses (algorithm design, data structure, object-oriented and so on) [2,3]. The premise of mastering programming is to master programming language well. In many programming languages, $C$ language is widely used and popularized for its flexibility and practicability. Almost any computer model and any operating system support the development of $\mathrm{C}$ language
[4]. In most foreign universities, the course of $\mathrm{C}$ language is also arranged as the entry course of program design. For example, the Wolverhampton University in the United Kingdom has arranged the $\mathrm{C}$ language programming course as an entry-level course; Kongju Communication Arts College in South Korea has arranged the C language programming course as an entry-level course; the Kokushikan University in Japan and the University of India have both taken $\mathrm{C}$ language programming as the basic programming language course [5].

It's reasonable for colleges and universities at home and abroad to choose $\mathrm{C}$ language program as the entry-level course of programming. We can see from the TIOBE world programming language ranking. Figure 1 shows the TIOBE index of the world's Top10 programming languages from 2002 to 2019. 


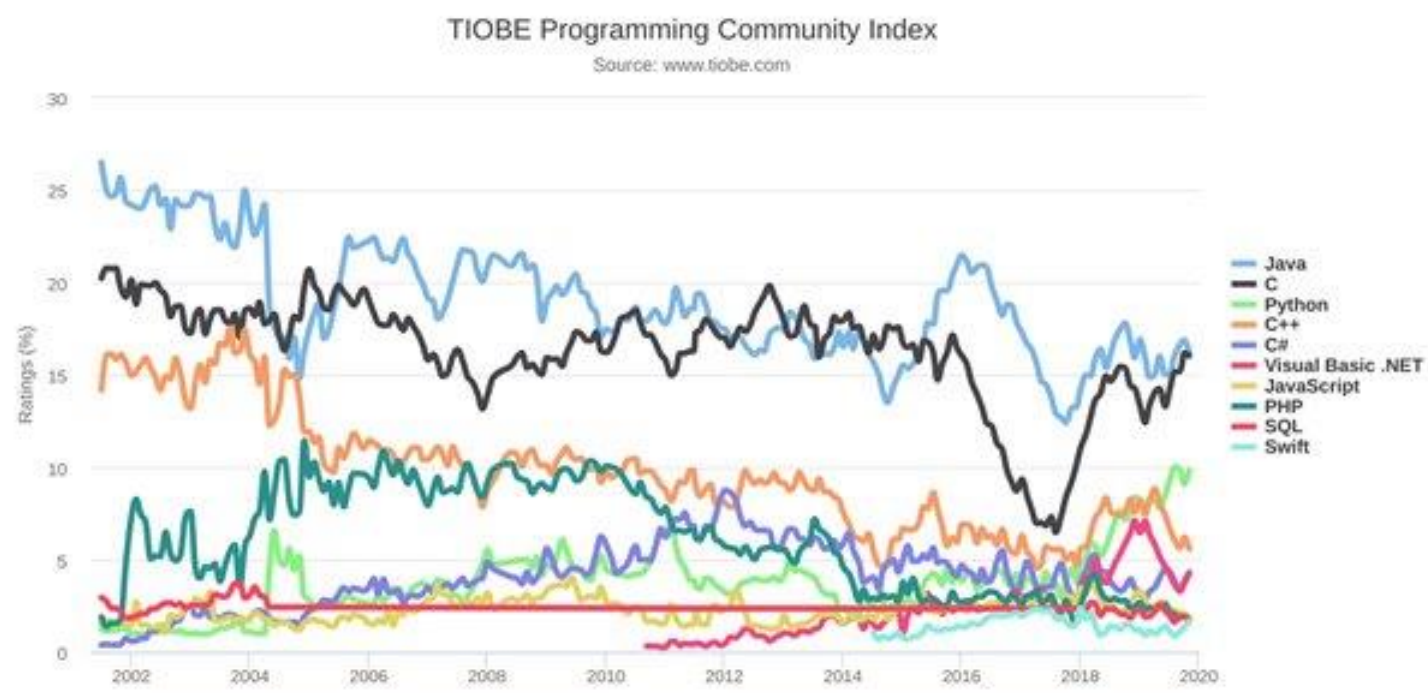

Figure 1 TIOBE index chart of the world's Top 10 programming languages (2002-2019)

The TIOBE world programming language ranking is an indicator of the popularity or popularity of programming languages. The ranking is updated every month based on the number of experienced programmers, business applications, courses, and third-party vendors on the Internet. This ranking uses well-known search engines such as Google, MSN, Yahoo!, Wikipedia, YouTube, Baidu, etc. [6]. As can be seen from the chart above of the TIOBE rankings, $\mathrm{C}$ programming has been ranked no. 1 or no. 2 from the past to the present. No matter how fast the software industry develops, programming languages remain unchanged, which seems to be an exception. At the same time, from this list, we can easily see the importance of $\mathrm{C}$ language in computer programming language from the past to the present, and we won't wonder why Chinese and foreign universities regard $\mathrm{C}$ language programming as the introductory course of computer programming courses [7]. The position of $\mathrm{C}$ language programming is so important, so it is necessary for us to explore the corresponding teaching methods to make students better accept and master the course, to improve and optimize the classroom teaching effect.

\section{CASE-BASED TEACHING METHODS AND GUIDING PRINCIPLES}

As an introductory course for freshmen, C language programming course has many problems in the teaching of local universities. (1) $\mathrm{C}$ language course itself has many and scattered knowledge points, and requires strong practical ability, so it is necessary to combine knowledge points with practical practice; (2) most of the students in local colleges and universities are from rural areas, and they have little contact with computers before entering the University, let alone understand programming language; (3) students in local colleges and universities lack independent learning ability, basically still stay in high school feeding learning mode, and even fear of programming language.

In view of the current situation and problems of computer students in local universities, it is necessary to explore a method which cannot only arouse students' interest but also improve their practical ability and knowledge points. Therefore, this paper mainly expounds the teaching method of combining case teaching and knowledge points to improve students' learning interest and practical ability.

The case-based teaching method is to use the combination of case and knowledge points to implement in the case, where the case can be task, topic or project. According to the teaching knowledge points, teaching contents and teaching objectives, collect, carefully construct and design the case projects simulating the instantiation scenes, set the tasks or problems of the corresponding knowledge points, so that students can fully integrate into the case tasks of specific or real scenes to learn. As the organizer of the case tasks, teachers guide students to analyze, explore, implement and Complete, etc. To effectively cultivate students' ability to learn knowledge points, find problems, analyze problems and solve problems [8]. This case-based teaching model was first proposed by Randall, former dean of Harvard Law School, and has been successfully practiced in the school of law, medical school and business school. Therefore, he is known as the "pioneer" of case teaching method. As one of the successful teaching models representing the future direction of education, case teaching method has been widely promoted to various universities in the world. The case teaching method is very suitable for engineering education major. This teaching method has the characteristics of flexibility, individuality and diversity $[9,10]$. Through the case task to promote the interaction and exchange between teachers and students, students and students, can effectively realize the combination of in class and out of class, theoretical knowledge points and practical operation case tasks, cultivate students' comprehensive 
application ability and practical innovation ability, and promote students to fully play the application of knowledge points in real case problems, so as to achieve students' mastery and comprehensiveness of knowledge points The improvement of application quality and ability $[11,12]$.

As a pilot course of programming language in local universities, it is very important to learn the $\mathrm{C}$ programming course well, which is directly related to the following professional courses. For the students of local colleges and universities, first of all, they should improve their interest in learning programming language and eliminate their fear of learning programming language. But it is not easy to learn $\mathrm{C}$ programming well, because $\mathrm{C}$ programming is a course that requires strong practical ability and logical thinking ability, and there are quite a lot of knowledge points. Therefore, in case-based teaching design, we should let students feel that programming linguistics is not difficult to imagine. Learning it can not only cultivate their logical thinking ability, but also cultivate their carefulness, patience, perseverance and self-confidence in the process of programming. At the same time, they can experience the hardships in the process of programming and writing and the joy of overcoming challenges Sense. In the teaching of case teaching in $\mathrm{C}$ programming training course, we should grasp the following principles:

(1) Case teaching should adhere to the principle of "taking case task as the main line, students as the main body and teachers as the guide". Students are the main body of teaching activities, and teachers only guide students to complete case work.

(2) Modularize knowledge points and establish the overall framework of knowledge point case task. Design case tasks, test data and test samples according to specific knowledge point syntax content. The design of case questions is very important. These questions should not only strengthen students' understanding and application of learned knowledge, but also promote students' further thinking and active exploration of new knowledge. At the same time, we should design cases according to different levels of learning ability of students, so that the cases can cover different levels of students from easy to difficult.

(3) When designing task assignments, knowledge points are abstracted into problems that need to be solved in reality, combined with practical application background, to stimulate and improve students' interest in learning.

(4) Use an online automatic judge system to promote students' learning initiative. By using the online automatic judge system, the designed case tasks and corresponding test cases of tasks are uploaded to the online automatic judge system, and the corresponding jobs are arranged according to the easy to difficult layers. When students are doing the corresponding level tasks, they submit the written program to the online automatic evaluation system. The system will give the program right and wrong in a few seconds, and give the corresponding prompt for the reason of the error, so that students can modify according to the error prompt. This can greatly arouse students' interest in learning, give them a sense of satisfaction and achievement in programming, and make them feel challenged in programming.

\section{CASE TEACHING DESIGN AND IMPLEMENTATION}

Case teaching method is mainly used in C programming training course, and the key point of the implementation of this method is the design of case task. First of all, modularize the knowledge of $\mathrm{C}$ programming training course. According to the knowledge points, the course is divided into several learning modules, including sequential structure module, selective structure module, cyclic structure module, a recursive program module, array module, function module, macro definition module, pointer module, structure module, file module, bit arithmetic module, etc. After the whole knowledge point modularization framework is built, the corresponding grammar details are added into the corresponding knowledge point module, and then the corresponding case task topic, test data and test samples are designed. For example, when we design the sequential structure program module, we add the definition and use of basic data types, the use of input and output statements, statements, identifiers and other detailed knowledge; when we design the selection structure program module, we add the relational operators, relational operation table expressions, logical operators and logical expressions and other detailed knowledge. According to each knowledge point module abstracted and combined with the actual application scenario, 20 to 30 related case program tasks are designed. In a semester, through repeated training of modular tasks, I believe that the vast majority of students can master the contents of the corresponding modular knowledge points, and can train students to have better programming ability.

Designing a scientific and practical case task assignment is the top priority of case teaching method, and the idea of each case task assignment needs to integrate the modular knowledge points we have divided above. In order to improve the students' interest in learning, for the knowledge points that have been modularized, we abstract the problems that need to be solved in reality when designing the case task assignment, and we can also integrate the more important current affairs activities into the task topics in the year. In this way, students can not only improve the ability of programming, but also know the practical use of programming, and improve their interest and motivation in learning. For example, when we design branch structure program tasks, we can design bank interest calculation by years, high-speed rail fare calculation by sections and miles, class student performance statistics by sections, simple computer design, etc. Such as, when designing tasks of functions and array contents, we can design them as countdown of 2014 Beijing APEC conference, audition of movie directors, 2D array storage processing in graphic application, etc. In this way, the task assignment is designed to be closely related to the practical application, so as to 
improve students' interest and enthusiasm for professional learning, promote students' thinking, improve students' ability to analyze and solve practical problems, let students know the practical application of this course, and let students have a sense of achievement in learning and practice.

Another key point of case teaching is the arrangement of case tasks. When designing case tasks, the learning objectives are divided into different levels, and appropriate basic objectives, development objectives and open objectives are proposed for students of different levels. On this basis, design a certain number of case assignments with a certain gradient, and require all students to complete the tasks corresponding to the basic goals. The students who have learned and thought will then complete the tasks corresponding to the next development goals that need to be completed with effort. The students who have learned and created should continue to complete the following open tasks. This way can drive students at all levels, neither make the students with strong learning ability feel too easy to relax their study, nor make the students with slightly poor learning ability feel too difficult to give up their study, and truly achieve the effect of teaching students according to their aptitude. For the $\mathrm{C}$ language programming training course, each knowledge point module is equipped with 20-30 case assignments, which are all in the form of groups. Generally, a knowledge point module is divided into three groups of tasks. The first group of simple case tasks requires that each student must complete them; the second group of comprehensive case tasks is more difficult than the first group of case tasks, requiring each student to complete as much as possible, requiring the students to think actively; the third group of case tasks is part of the topic of optional work, only for students with spare power to further complete, so as to achieve the goal of improving knowledge Mark. The hierarchical grouping of case tasks is shown in Figure 2.

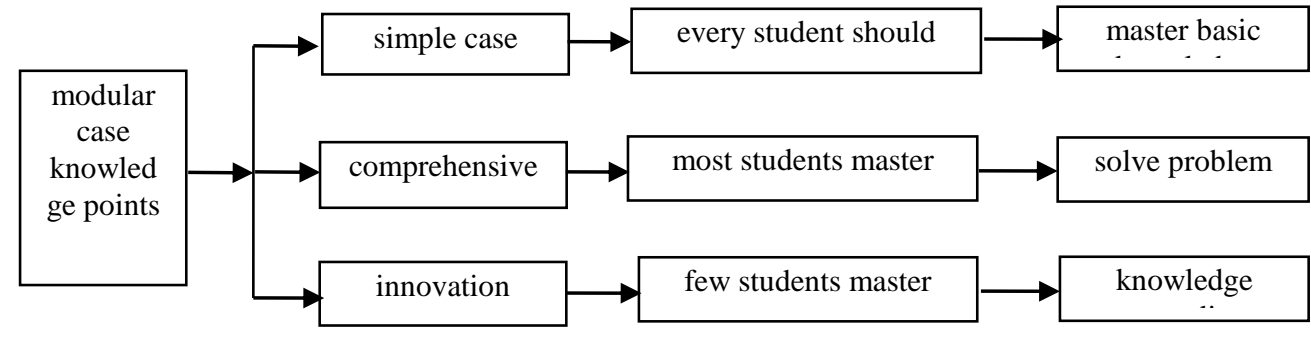

Figure 2 Case group diagram

In view of the requirements of the above description of case task design, the following is a specific case design to illustrate the key points in case design. The following is an example of selecting structural knowledge points to design this case.

Title: college entrance examination English level

Topic Description: in 2014, the Ministry of Education issued the cancellation of the English examination for the senior high school entrance examination. Since 2018, the English entrance examination for senior high school has been changed to the socialized graded examination. The socialized examination means that English is not included in the total score since the 2017 entrance examination, and the examination method is socialized. You can participate twice a year and get the best score ranking. In the 2018 college entrance examination, English will be divided into six grades, A, B, C, D, E, F. Each grade represents the corresponding score and ranking ratio. At present, the Ministry of education stipulates that the total score of English is 100, of which 90-100 is A level, 80-89 is B level, 70-79 is C level, 60-69 is D level, 40-59 is E level, 0-39 is F level. Now I want you to compile a program to automatically judge the grade of college entrance examination English.
Input Description: the input contains multiple lines (each line represents a test case), and each line enters an English score for college entrance examination.

Output Description: each line outputs a corresponding grade of college entrance examination English score. (Note: output error when input score is greater than 100 or less than 0)

Sample input 1:90

Sample output 1: A

Sample input 2:50

Sample output 2: E

Sample input 3:130

Sample output 3: error

In the above case design, the main knowledge point of examination is to select structural sentences, but in the case, the real current situation scene - the reform level examination of English college entrance examination is added, which makes students have a higher enthusiasm and interest in programming. In addition, multiple samples are used in the output samples, and each sample will have corresponding scores when it is correct, which can not only test the comprehensiveness of students' knowledge points, but also arouse students' confidence in overcoming the problem.

In addition, after all the cases are designed and grouped, they are uploaded to the online judge system. Students 
submit programs on the online judge system. The online judge system can immediately identify the right and wrong of the programs, so that they can give back to the students in time, and then modify the programs according to the error prompts, which can greatly mobilize students' interest in learning, give them satisfaction, and let students have a sense of challenge.

\section{THE EFFECT AND ANALYSIS OF CASE TEACHING}

Since 2013, the final examination of C language programming course in our school has been conducted in the way of joint examination with Hunan Agricultural University and Jishou University. The final examination questions are written by each school in turn, and the teachers who take part in the questions are the teachers who are not responsible for the course of this semester. In 2018, there are 7 classes of $\mathrm{C}$ language programming in our school of computer science, among which class 1 , class 2 , class 3 and class 4 are computer science and technology, class 5 are network engineering, class 6 and class 7 are software engineering. In 2018, I served as a teacher in class 1 and class 2 of computer science and technology in $\mathrm{C}$ language programming. The other five classes were taught by three other teachers. In the $2018 \mathrm{C}$ language programming training, I used the case method to teach, and all cases were uploaded to the online judge system.

The following is mainly from two aspects to evaluate and analyze the teaching effect of case teaching method. On the one hand, it analyzes the teaching effect of case teaching method from the students' homework completion and questionnaire survey; on the other hand, it analyzes the teaching effect of case teaching method from the students' final examination results.

\section{DAILY TASK COMPLETION}

I will arrange three groups of case assignments in each knowledge point module, simple, medium and difficult questions that need to be considered. Each group has 7-8 questions, and each group of case assignments has a time limit of 1-2 weeks. Figure 3 shows the statistics of students' completion of homework within the specified time.

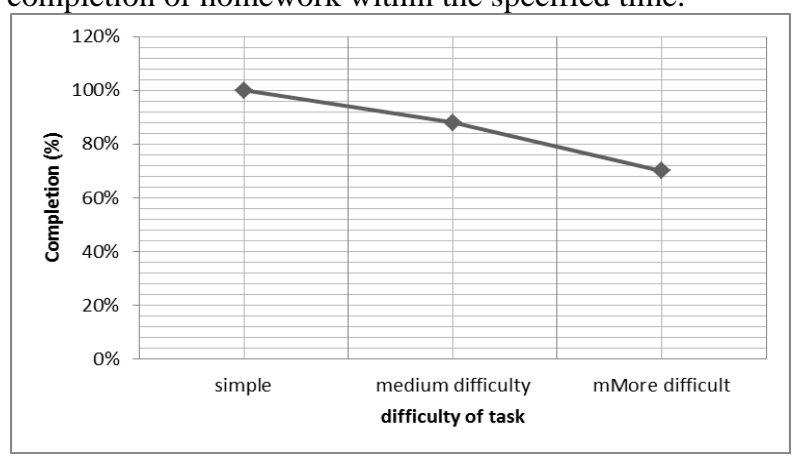

Figure 3 Daily task completion

From the completion of normal assignments, such a layered design method is still very good, and also basically meets the requirements of teaching design. Basically, all the students can complete the simple homework tasks. A few of the students who have completed the more difficult homework tasks haven't finished them. Of course, some of the students who have completed the homework may ask others, and they haven't fully understood it, but at least they have spent time and effort learning programming.

In addition, we will organize a student forum in the middle of a semester to learn about students' learning and teachers' teaching. From the symposium, we know that students' feedback on the case teaching method of $\mathrm{C}$ programming training is quite acceptable and satisfactory. Through the combination of online judge system and knowledge point cases, students' enthusiasm and interest in learning can be better aroused, and students can also better experience the sense of challenge and joy after the success of the challenge.

\section{FINAL EXAM RESULTS}

In the final examination, we adopt the way of joint examination of three schools. The examination separates theory from practice. The types of questions in the theoretical examination paper include multiple choice questions, judgment questions, filling in blank questions, reading program writing result questions and program filling in blank questions. The types of practical training papers mainly include program design questions and program function questions. The examination adopts the online automatic judge examination platform. There are many samples for each question of the practical training examination, and each sample is set with a certain score. The corresponding score can be obtained through one sample. Only when all the samples of the subject pass can the whole part of the subject be obtained. Figure 4 shows the passing rate and the total passing rate of all classes in our school.

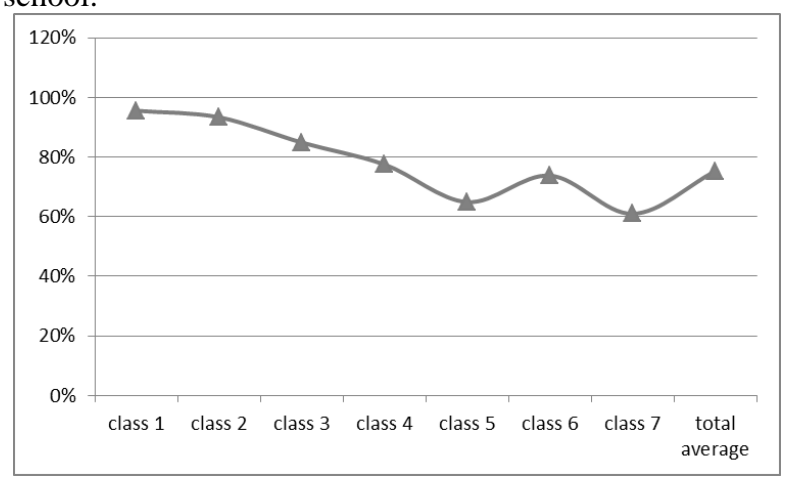

Figure 4 Passing rate of each class in final examination

I teach classes 1 and 2 in this teaching arrangement. I use case teaching method in classes 1 and 2 . From the final exam results of the practical training, we can see that the 
exam results are the best in all classes. We can see that the teaching effect of using case teaching method is considerable. The case teaching method is also worth popularizing and applying. Of course, a teaching method cannot completely determine the results of an examination, because there are many other factors affecting the test results, and case teaching method is only one of them.

\section{SUMMARY}

In view of the weak foundation of the students majoring in Computer Science in local colleges and universities, there is a certain sense of difficulty and fear in learning the $\mathrm{C}$ language programming course. In this paper, case-based teaching method is used to stimulate students' learning autonomy and learning motivation, so as to improve students' practical ability and programming thinking in programming. By taking the case task as the carrier, combining the case task and knowledge points, the corresponding curriculum knowledge points are organically integrated into the case. At the same time, the case is divided into three levels: simple, general and slightly difficult to deal with different levels of students. All cases are arranged on the online automatic judge system. Students complete case task assignments through the online automatic judge system, so that students can better learn knowledge points and complete project cases, and students can better experience the sense of challenge and joy after the success of the challenge. Through the test of the completion of homework and the final exam results, the case teaching method can achieve good teaching results, which can better arouse students' enthusiasm for learning and train students' practical ability of hands-on programming.

\section{ACKNOWLEDGEMENT}

The Research was supported by Hunan University Education Science Planning Project(XJK18QGD009); This research was financially supported by Huaihua University Teaching Reform Project(Research on case teaching method of advanced language programming training (C language)); This research was financially supported by Huaihua University Teaching Reform Project (Research and Practice on the training mode of computer applied innovation and entrepreneurship talents under the background of new engineering). This work was supported in part by the Huaihua University Double First-Class Initiative Applied Characteristic Discipline of Control Science and Engineering.

\section{REFERENCES}

[1] Zhou Xiaoqing, Li Hong, Ye Ansheng. Exploration and Practice on Task-driven Project Case Teaching Method in Revolution of Course Teaching[J]. Experiment Science \& Technology, 2018, (4):101-106.

[2] Chen Xin. Case teaching design of programming language[J]. Journal of Changzhi University, 2018, (2):57-58.

[3] Zhao Xingzhi, Fang Li, Yang Yong, Yang Jing. Task driven teaching reform and practice of $\mathrm{C}$ language programming $[\mathrm{J}]$. China new communication, 2018, (19): $183-184$.

[4] Li Wenquan, Xu Suping. Research on Hybrid Teaching Reform of $\mathrm{C}$ language programming [J]. Computer knowledge and technology, 2018, (30): 176-177.

[5] Abu litfu, esmobi. The application of "project introduction task driven" teaching method in the teaching of C language programming [D]. Xinjiang: Xinjiang Normal University, 2016: 1-80.

[6] Zhou Xujun. Design and application of $\mathrm{C}++$ Teaching in junior high school based on task driven Teaching [D]. Chongqing: Chongqing University, 2017: $1-61$.

[7] Xu minlan. Classroom organization and effect evaluation analysis of "case lecture" + "case discussion" Teaching [J]. Education and teaching forum, 2019, (4): 209-211.

[8] Lan Li, Hu Xiaohui. Key teaching links of improving "C language programming" course based on "rain class" in the context of engineering certification [J]. Computer age, 2019, (1): 102-104.

[9] Liu Yuelin, Zhou Guohua, Gao Junji, Zhao Wenchun. Exploration of practical teaching innovation mode guided by practical teaching [J]. Journal of higher education, 2019, (2): 22-24.

[10] Zhao Suping. Case driven teaching method of case nesting [J]. Modern computer, 2018, (26): 70-73.

[11] Black horse programmer. C programming case course $[\mathrm{M}]$. Beijing: People's post and Telecommunications Press, 2017.01.

[12] Huang Li, Zhang Kai, Hu Wei, Wang Xiaofeng. C language online training course research for new 
engineering $[\mathrm{J}]$. Curriculum education research, 2018, (18): 29-30. 